American Journal of Nanotechnology 2 (1): 94-99, 2011

ISSN 1949-0216

(C) 2011 Science Publications

\title{
A Drives and Control Integrated Time-Domain Dynamic Analysis and Modeling Approach Applied To Ultra-Precision Machine Tools
}

\author{
${ }^{1}$ Tianjian Li, ${ }^{1}$ Shijin Chen, ${ }^{2}$ Haijun Zhang and ${ }^{3}$ Kai Cheng \\ ${ }^{1}$ Mechatronics Engineering, Harbin Institute of Technology, Harbin 150001, China \\ ${ }^{2}$ Research Center of Laser Fusion, China Academy of Engineering Physics, \\ Mian Yang 621900, China \\ ${ }^{3}$ Department of Engineering and Design, Brunel University, \\ Uxbridge, Middlesex UB8 3PH, UK
}

\begin{abstract}
Problem statement: Machines dynamic performance depends not only upon the mechanical structure and components but also the drives and control system. However, the design of the machines is still at the nascent stage by working on an individual machine basis, hence lacks generic scientific approach and design guideline. Approach: Using computer models integrated drives and control system to predict the dynamic performance of ultra-precision machine tools can help manufacturers substantially reduce the lead time and cost of developing new machine. This study proposed a holistic integrated dynamic design and modeling approach, which supports analysis and optimization of the overall machine dynamic performance at the early design stage. The modeling and simulation process on an ultra-precision lathe machine tool is presented using the proposed approach. Results: Model of an ultra precision machine tool is established and used to predict the overall machine performance of the configuration. Deformations of base and fixed sideways in motion are calculated to demonstrate the valid of the method. Conclusion: Excellent accuracy on motion deformation is achieved. The designed and implemented integrated time-domain dynamic analysis and modeling system can predict the static and dynamic performance of ultra-precision machine tools, which can reduce the lead time and the cost of developing new machine.
\end{abstract}

Key words: Integrated modeling, ultra-precision, time-domain data, control integrated, Computer Assisted Design (CAD), Computer-Assisted Manufacturing (CAM), Computer Numerical Control (CNC), Computer-Assisted Engineering (CAE), drive systems, dynamic performance

\section{INTRODUCTION}

Development of new engineered product offers several opportunities for the use of simulation and computational modeling. A typical design and manufacturing cycle requires the product first to be modeled using Computer Assisted Design (CAD) software, as either a solid model or a B-rep model, which can be used for geometric analysis. The same product then needs to be represented in ComputerAssisted Engineering (CAE) software, typically as a finite element mesh, which can be used to conduct distortion analysis during and after manufacturing. The model then is represented in Computer-Assisted Manufacturing (CAM) software, typically as a solid model, to determine the optimal tool path for machining. Finally, the machine tool controller instructions need to be generated using the tool path model to drive a Computer Numerical Control (CNC) machine to complete the manufacturing process (Altintas et al., 2005; Glotzer, 2009).

Simulation and modeling are integral to every engineering activity. While the use of simulation and modeling has been widespread in engineering, there are several major hurdles still present in the effective use of these tools. First, effective workflow methods need to be developed to aid in developing simulations for complex systems. The CAD-CAECAM-CNC model should be instead to a more efficient approach, Zaeh and Siedl (2007) has proposed a new method for simulation of machining performance by integrating finite element and multi-body simulation for machine tools, but the control system in the machine has not been taken into considered.

Visualization of simulation outputs remains a challenge. Two-dimensional illustrations are proverbial (Wang, 2010), in the same time WYSWYG for the machine analysis and modeling is still at the nascent stage. 
Links between subsystem- and system-level simulations are weak, machine tool design, analysis, optimization and performance evaluation are performed on mechanical systems and control systems individually (Zhou, 1998; Lan, 2010; Luo et al., 2005). The performance of machine combines cannot be evaluated accurately.

In this study, a drives and control system integrated modeling and analysis approach for time-domain dynamic analysis is proposed and employed in evaluation of an ultra-precision machine. The proposed approach permits analysis and modeling of the overall machine tool dynamics and machining performance prior to prototyping. In addition, the dynamic performance can be evaluated in visualized illustrations for the weakness point of the machining, such as every part stress or strain in working, which also can used to be expressed clearly on an existed machining.

\section{MATERIALS AND METHODS}

A number of methodologies and utility software do exist for deployment in different application areas and in different corporate cultures (Norton, 2008). But all of the currently available techniques of machine performance study suffer from many serious drawbacks such as low output synchronism and a large set of the spurious signals (Chan, 2001). Further all of the techniques used so far are analog based techniques which typically require disproportionately on physical model. None of the available techniques is thus considered entirely satisfactory.

A typical precision machine tool integrated model should be considered to consist of three major subsystems. These are mechanical structure, spindle and drive system and control system (Fig. 1). These subsystems interact and determine the machining mechanics dynamics and the machine tool's performance.

Model methods of the machine's mechanical structure: Proper modeling and analysis of the mechanical structures are critical since the mechanical structure not only provides the support and accommodation for all the machine's components but also contributes to dynamics performance. The machine's mechanical structure is imported from the CAD parts which are designed with Catia to effective evaluate the machine performance.

Model methods of the drive and electrical components: The selection and use of any functions depends primarily on the type of problem under study. For instance, while some sets render rather simple and useful solutions to a certain problem, other sets give complicated and less useful forms of solution. Computation models of an existing machine (Fig. 2) are utilized in the new approach interpretation to simplify and to compare.

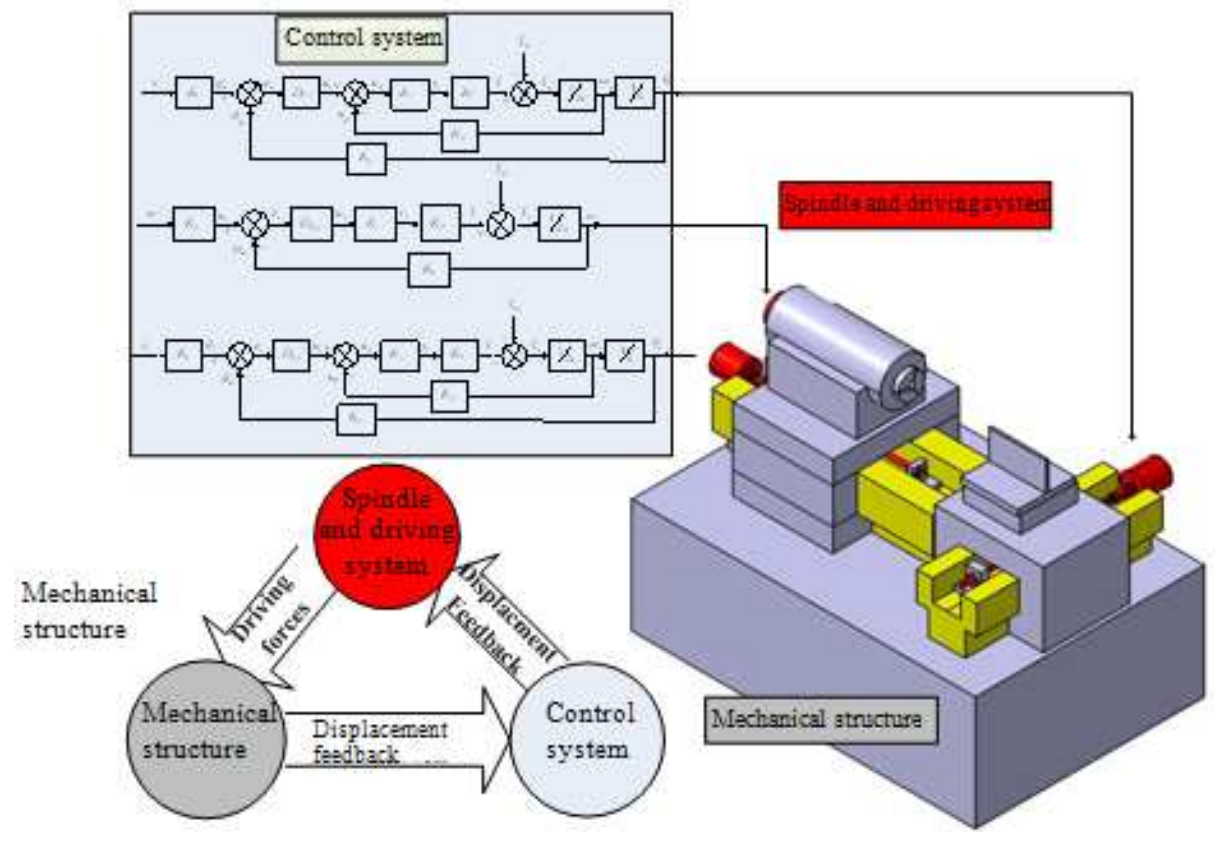

Fig. 1: A typical precision machine tool integrated model 
Drive systems: Aerostatic bearings and screw-based drive systems have been used on the linear axes. The stiffness of drives is primarily dependant on the control system, the drive motor, amplifier and encoder. Therefore, the dynamic stiffness of a servo loop becomes very important in achieving high performance micro machining. An accurate dynamics model is necessary to predict dynamic performance in the feed direction of the slide. The slide control system model is shown in the block diagram of Fig. 3.

The following transfer function is obtained from Fig. 3:

$$
\mathrm{G}_{\mathrm{s}}(\mathrm{s})=\frac{\theta_{\mathrm{x}}(\mathrm{s})}{\mathrm{u}_{\mathrm{r}}(\mathrm{s})}=\frac{\frac{1}{\mathrm{~K}_{2}}}{\mathrm{~s}\left(\frac{\mathrm{J}}{\mathrm{K}_{\mathrm{v}} \mathrm{K}_{\mathrm{T}} \mathrm{K}_{2}} \mathrm{~s}+1\right)}
$$

Spindle: control mode of spindle speed is closed and is shown in Fig. 4. The control strategy used for velocity loop control is classical PID. To simplify model, spindle motor driver is seen as proportion.

So, the transfer function is represented as:

$$
\mathrm{G}_{\mathrm{p}}(\mathrm{s})=\frac{\omega_{\mathrm{s}}(\mathrm{s})}{\mathrm{u}_{\mathrm{r}}(\mathrm{s})}=\frac{\mathrm{K}_{\mathrm{v}} \mathrm{K}_{\mathrm{T}}}{\mathrm{Js}}
$$

Where:

$\mathrm{Kv}=$ Proportional coefficient on velocity gain

$\mathrm{K}_{\mathrm{T}}=$ Operates on the electric flow gain

$\mathrm{J}=$ Roll inertia of spindle motor

All the parameters used in the modeling were obtained from the manufacturers' data.

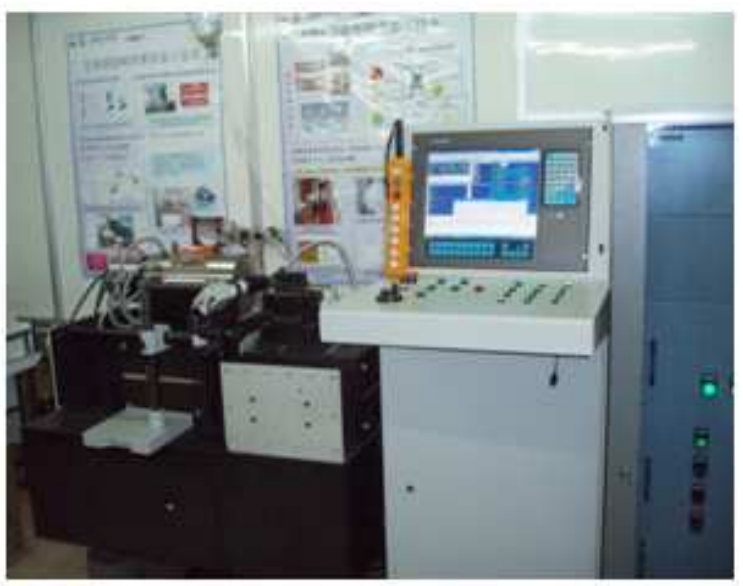

Fig. 2: Prototype of the drive and electrical model

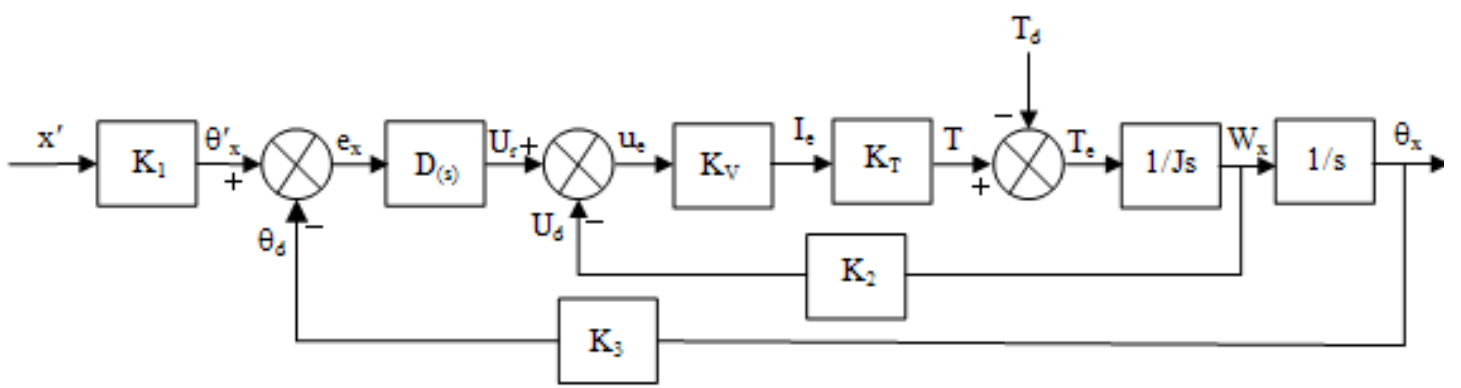

Fig. 3: Dynamic model of slide control system

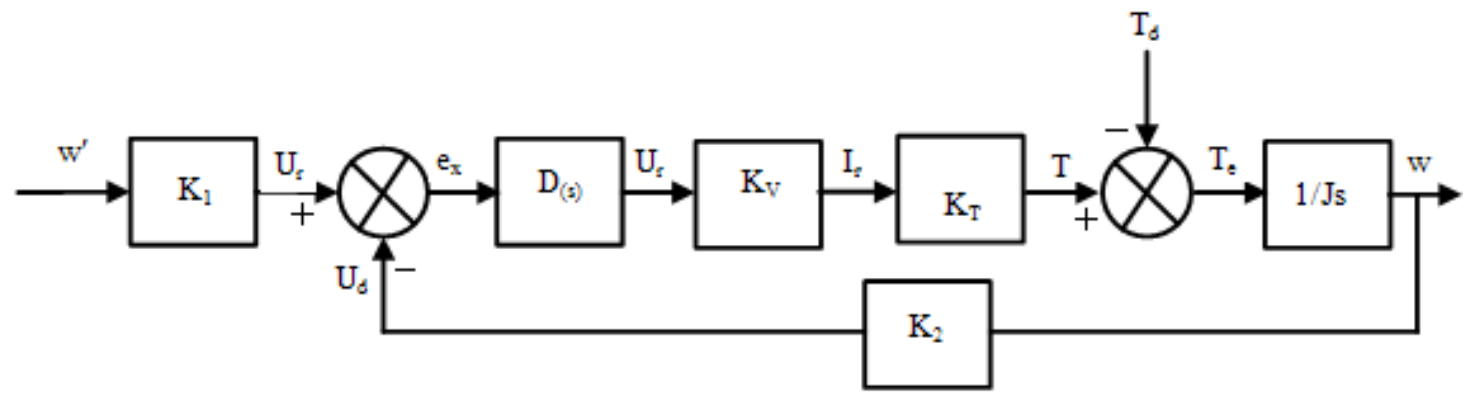

Fig. 4: Dynamic model of spindle control system 
Model methods of environmental interferer: Diamond Ultra-precision machining process is very sensitive to environmental vibration, which is the main reason for the isolation of ultra-precision machine tools form the environment. Environment interferes with the process and exists in all directions. In ordinary process, surface morphology is mostly effect by vibration environment on $\mathrm{Z}$ axis. Therefore, many scholars only consider the environment vibration on $\mathrm{Z}$ axis direction and ignored the environment vibration on the other two directions. But to microstructure surfaces machining, every direction of the environment vibration produce important influence, therefore, the simulation system will be imposed environmental interferer on the $\mathrm{X}, \mathrm{Y}$ and $\mathrm{Z}$ direction respectively. Environmental interferer is expressed by (Luo et al., 2005; Thomas and Beauchamp, 2003):

$\Delta \mathrm{E}_{\mathrm{e}}=\frac{1}{2} \mathrm{E}_{\mathrm{epv}} \sin \left(2 \pi \mathrm{F}_{\mathrm{e}} \mathrm{t}+\varphi\right)$
Where:

$\Delta \mathrm{E}_{\mathrm{e}}=$ Environment vibration error

$\varphi \quad=$ Phase offset

$\mathrm{E}_{\mathrm{epv}}=$ Maximum error for the environment vibration value, in this study, $\mathrm{E}_{\mathrm{epv}}=0.04 \mu \mathrm{m}$

$\mathrm{F}^{\mathrm{e}} \quad=$ Environment vibration frequency, $\mathrm{F}_{\mathrm{e}}=5 \mathrm{~Hz}$

\section{RESULTS}

To explained that the method presented in this study, a example of performance analysis of ultraprecision lathe machine tool as flexible body under the axis moving condition is shown in Fig. 5. In this case, a simple axis moving process was chosen, because the calculation time is very high. The step from frequencyto time domain, makes great demands on the simulation system. This is the first step to predict the performance of machine tools during machining real parts in the whole workspace.

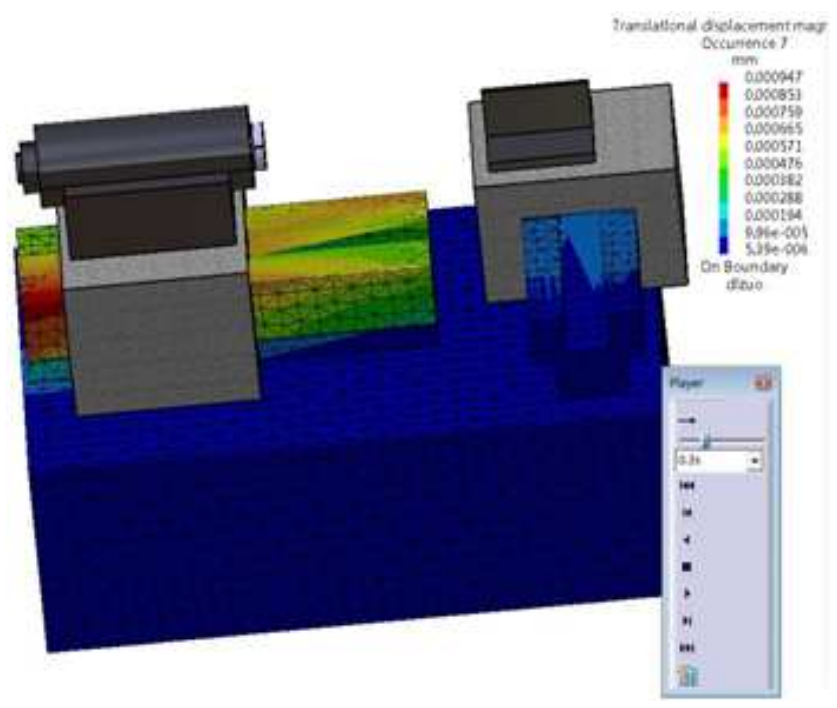

Fig. 5: Screenshot of the virtual machine tool in analysis
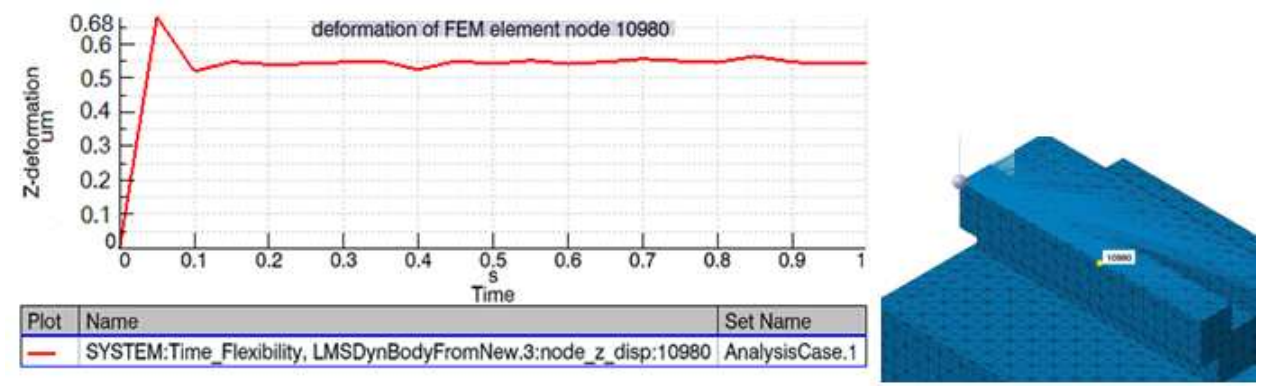

Fig. 6: Deformation in motion of a point on fixed slide way 


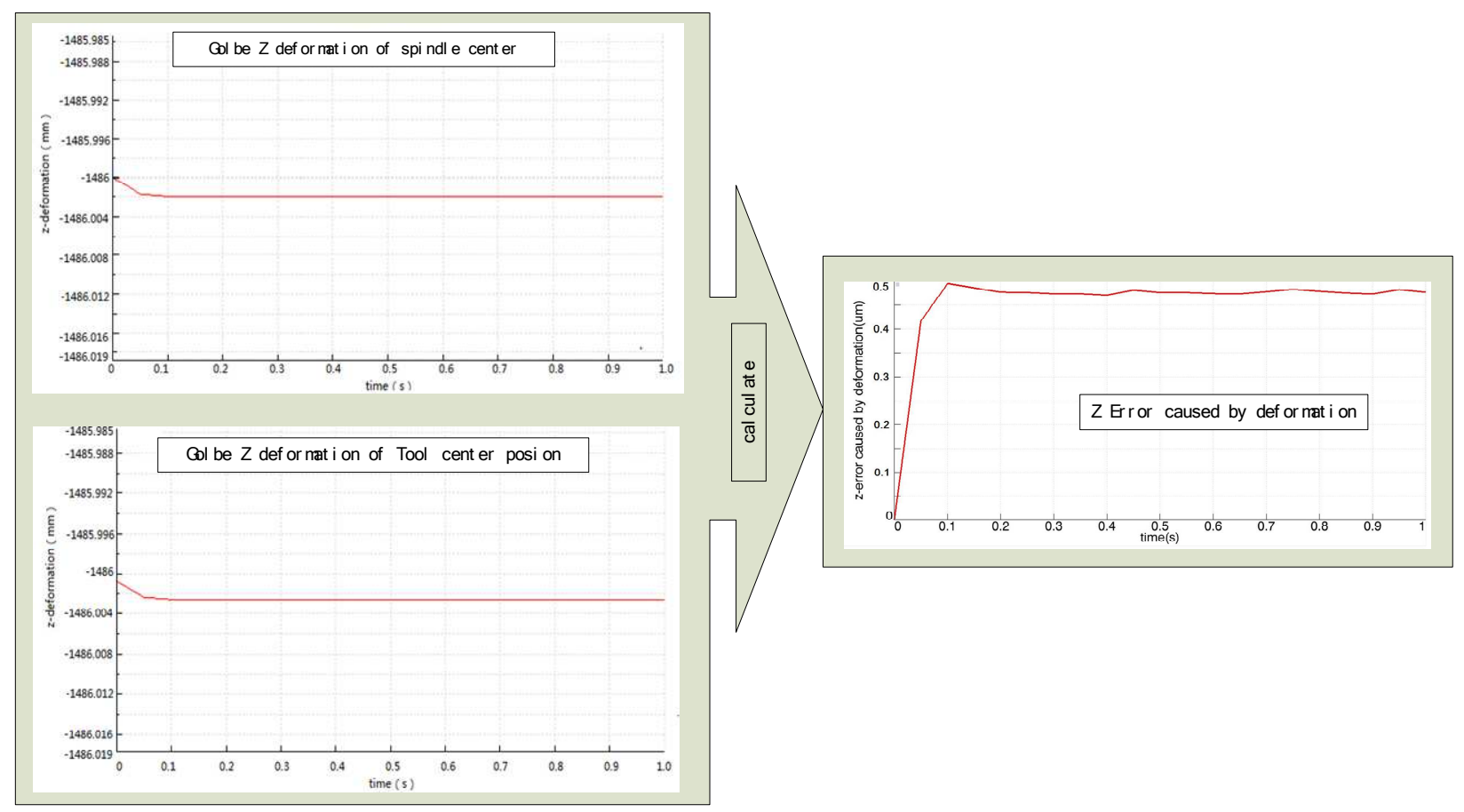

Fig. 7: Globe deformation in $\mathrm{Z}$ direction between tool center position and spindle center

The deformation on base and fixed slide ways is showed in Fig. 5, which is derived out with feedback to compensate. Analysis of any other parts can also been executed in same way. Therefore, with this approach it is possible to predict and compensate the deformation of the whole machine in moving.

Figure 6 shows deflection on $\mathrm{Z}$ direction of a point on fixed sideway (position is marked out in the right of Fig. 5) under changed condition from standstill into uniform motion obtained by increasing the velocity instantaneous. The peak deformation value is at $0.68 \mu \mathrm{m}$, which is calculated with weight of the Spindle Box and attachment. With time going on, motion of the axis becomes stabilized and the deflection is declined to $0.55 \mu \mathrm{m}$. Because of vibrate caused by control system and environment variable, the deformation is not a constant.

Deformations of tool center position and center of spindle can be obtained after flexible body design on the entire model. The results of the example machine tools deformation in motion are given in Fig. 7. Left data are fetched directly in analysis model and the right can achieve after straightforward computing using the left analysis results. So, the height-regulating device under the tool rest bracket should be increased $0.47 \mu \mathrm{m}$ than value calculated in CAD geometry of structurecontemplated influence of deformations. This result is coincidence with data measured in machining form the machine tool (Fig. 2).

\section{DISCUSSION}

A drives and control integrated time-domain dynamic analysis and modeling approach has been demonstrated. A computer model with machine structure drives and control system has been successfully developed to predict the dynamic performance of ultra-precision machine tools. Series of simulations have been executed with varied forces, loads, velocities, positions. Using the simulation result of proposed model both of the control model and machine structure can be estimate and modified.

The main result of this study is time-domain dynamics analysis on complete machine as flexible bodies under the axes moving condition. The accuracy of the method meets the demands of simulating machine tools and other high performance production systems. Errors on tool centre position can be calculated in any time and position in motion, which provided effectively error compensation data to improve accuracy. The described techniques can be used in all relevant components in the machine tools.

As has been proved, the approach may have practical importance in design and analysis. Using data getting from analysis manufactures can instead physical prototype with computer model and can provide compensation data as directive standard in parts processing. 


\section{CONCLUSION}

A computer models integrated drives and control system to predict the dynamic performance of ultraprecision machine tools has been successfully developed for design before the physical product presented.

Excellent accuracy on motion deformation is achieved. The designed and implemented integrated time-domain dynamic analysis and modeling system can predict the static and dynamic performance of ultraprecision machine tools, which can reduce the lead time and the cost of developing new machine. The described techniques can be used in all relevant components in the machine tools.

\section{REFERENCES}

Altintas, Y., C. Brecher and S. Witt, 2005. Virtual machine tool. Ann. CIRP, 54: 651-674. DOI: 10.1016/S0007-8506(07)60022-5

Chan, F.T.S., 2001. Modeling of integrated, distributed and cooperative process planning system using an agent-based approach. Proc. Instit. Mech. Eng.. J. Eng. Manufac., 215: 1437-1451. DOI: $10.1243 / 0954405011519060$

Glotzer, S.C., 2009. International Assessment of Research and Development in Simulation-Based Engineering and Science. World Technology Evaluation Center Report. http://www.wtec.org/reports.htm
Luo, X., K. Cheng and R. Ward, 2005. The effects of machining process variables and tooling characterization on the surface generation: Modeling, simulation and application promise. Int. J. Adv. Manufacture Technol., 25: 1089-1097.DOI: 10.1007/s00170-003-1943-0

Lan, T.-S., 2010. Parametric deduction optimization for surface roughness. Am. J. Applied Sci., 7: 12481253. DOI: 10.3844/ajassp.2010.1248.1253

Norton, R.L., 2008. Design of Machinery: A Introduction to the Systematic and Analysis of Mechanisms and Machines. 4th Edn., McGrawHill, Inc., ISBN: 0073121584, pp: 825.

Thomas, M. and Y. Beauchamp, 2003. Statistical investigation of modal parameters of cutting tools in dry turning. Int. J. Mach. Tools Manufacture, 43: 1093-1106. DOI: 10.1016/S0890-6955(03)00131-7

Wang, Z., 2010. Design and development of a precision machine tool using counter motion mechanisms. Int. J. Mach. Tools Manufacture, 50: 357-365. DOI: 10.1016/J.IJMACHTOOLS.2009.10.014

Zaeh, M. and D. Siedl, 2007. A new method for simulation of machining performance by integrating finite element and multi-body simulation for machine tools. Ann. CIRP, 56: 383386. DOI: 10.1016/J.CIRP.2007.05.089

Zhou, Z., 1998. Principles Of Metal Cutting, Shanghai. Shanghai Science and Technology Press. DOI: 75323-3258-6,TG501 